\title{
The Prevalence of Hypertension among Individuals Aged Between 20-65 Years and Affecting Factors
}

\author{
Güllcan Çiftçioğlu ${ }^{1}$, Vasfiye Bayram Değer ${ }^{2 *}$, Sema Çifçi ${ }^{3}$ and Aynur Güneş ${ }^{4}$ \\ ${ }^{1}$ Department of Nursing, Faculty of Health Sciences, Nursing Management, Mardin Artuklu University, Turkey \\ 2,3Department of Nursing, Faculty of Health Sciences, Public Health, Mardin Artuklu University, Turkey \\ ${ }^{4}$ Department of Nursing, Faculty of Health Sciences, Health Law, Mardin Artuklu University, Turkey
}

Submission: July 22, 2020; Published: August 19, 2020

"Corresponding author: Vasfiye Bayram Değer, Department of Nursing, Faculty of Health Sciences, Public Health, Mardin Artuklu University, Turkey

\begin{abstract}
Hypertension is a significant public health problem that is widespread in our country as well as all around the world. This study was aimed to evaluate the prevalence of hypertension and affecting factors among the individuals aged between 20 and 65 years in the district of Artuklu, Mardin. The population of this cross-sectional study consists of individuals aged between 20 and 65 years $(\mathrm{N}=86245)$ in the district of Artuklu, Mardin. By using the Epi Info Statcalc calculation software, the number of participants ( $\mathrm{n}=1055)$ was determined with an unknown prevalence of 50\% with 0.003 error margin at a 95\% confidence interval. After being informed of the research, individuals aged between 20 and 65 years who agreed to participate were included in the sample. A questionnaire form including 27 items derived from the literatüre about hypertension containing socio-demographic characteristics and early diagnosis methods was used to collect the data. The data were analyzed using Statistical Package for Social Science for Windows (SPSS 16.0) program. It has been concluded in this study that the prevalence of hypertension is increased by age as in previous studies and there is a significant correlation between educational level and presence of hypertension. The rate of those who have never had their blood pressure measured was found to be high. According to the new hypertension guidelines of the American Society of Cardiology, $62 \%$ of the participants were found to be hypertensive. Since hypertension is a modifiable and preventable health condition, efficacious, publicly appreciated and feasible community-based protection and educational projects should be implemented.
\end{abstract}

Keywords: Hypertension; Prevalence; Mardin

\section{Introduction}

Hypertension is a chronic disease that is prioritized for public health since it is a preventable and controllable disease as well as leading to significant morbidity and mortality worldwide [1]. Hypertension [2], one of the leading risk factors for preventable causes of death, accounts for $6 \%$ of adult deaths worldwide $[3,4]$. According to the World Health Organization, hypertension ranks first among the preventable causes of death in the world [5]. The prevalence of hypertension tends to increase with age, rising sharply after age 50 , and affecting $50 \%$ of this population [5]. Unless effective measures are taken, the prevalence of hypertension will continue to increase as the world population grows older [3]. Epidemiological data indicate that the prevalence of hypertension which is $20-25 \%$ at the age of 30 s is increased significantly with age, reaching $50 \%$ at the age of 60 and over [6]. Approximately 7.1 million deaths per year are thought to be caused by hypertension [5].
There are only 3 large scale studies that will provide information on the prevalence of hypertension. Of these studies, the oldest but THE one with the longest follow-up period is the TEKHARF. Other studies are Turkey Hypertension Prevalence Study (a patent study) and Metabolic Syndrome Prevalence Survey among Turkish Adults (METSAR). According to the results of TEKHARF study, the prevalence of hypertension is $33.7 \%$ in Turkey. This rate varies from one region to the other. While it is less than 30\% in Southern Anatolia, it is more than $40 \%$ in Northern Anatolia. When the adult population was evaluated according to gender and decades of age, it was found that the prevalence of hypertension is increased by aging and is more common among the women of every age group than men. According to the results of the Turkey Hypertension Prevalence Study (a patent study), it is seen that the prevalence of hypertension is $31.8 \%$ in terms of age and gender. The prevalence was found to be higher than 
general with a rate of $36.1 \%$ among women while it was found to be lower than general with a rate of $27.5 \%$ among men. It was found in Metabolic Syndrome Prevalence Survey among Turkish Adults (METSAR) which was carried out throughout Turkey with a sample of 4261 participants that the prevalence of hypertension was higher than previous studies. While the average prevalence was $41.7 \%$ in the adult population, it was $44.3 \%$ in rural areas and $40.4 \%$ in urban areas [7].

The hypertension is generally defined as high blood pressure with systolic 140 and / or diastolic $90 \mathrm{~mm} / \mathrm{Hg}$ and above in all Hypertension (HT) guidelines. In the 2013 ESC classification, the equivalent of 'Normal and High normal' groups appear as
'Prehypertension' group in JNC 8. In the 2013 ESC / ESH guidelines, outpatient and home blood pressure measurements were more emphasized in the diagnosis of hypertension, and their usage and methodology were more clearly expressed see Table 1 [5]. However, according to the American Society of Cardiology's new hypertension guidelines, our previous information has changed radically. The new guidelines suggested that hypertension limits were lowered. While above $140 / 90 \mathrm{mmHg}$ was previously defined as hypertension, below $120 / 80 \mathrm{mmHg}$ was classified as normal and $120-129 / 80 \mathrm{mmHg}$ as hypertension. According to the previous definition, while 30 percent of the population is hypertensive, this rate has increased up to 46 percent with the new definition [8] (Figure 1).

\section{Blood Pressure Categories}
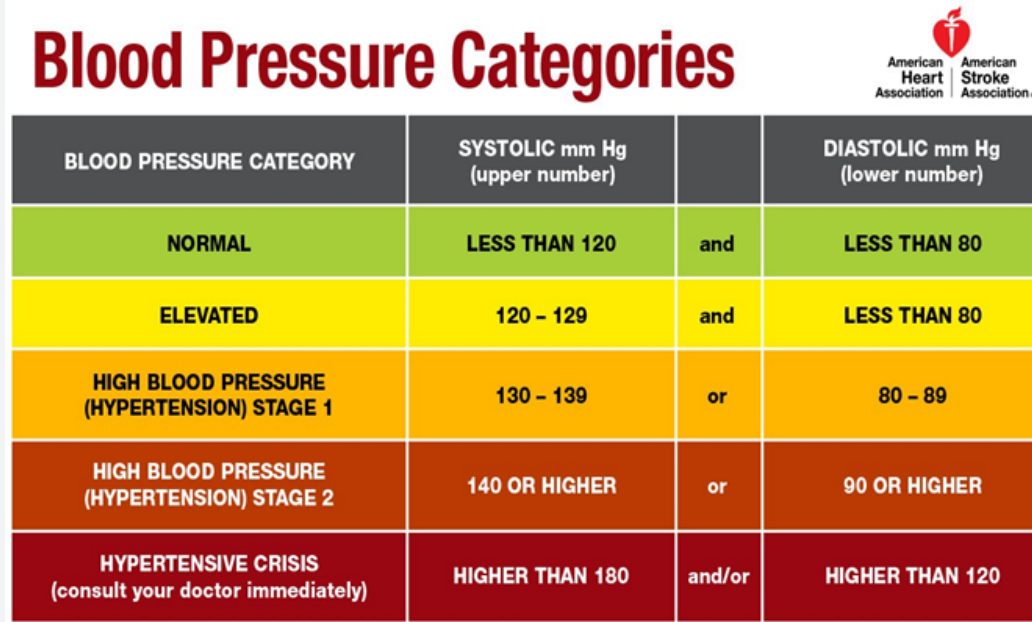

DIASTOLIC mm Hg (lower number)

LESS THAN 80

LESS THAN 80

$80-89$

90 OR HIGHER

HIGHER THAN 120

Figure 1: American Society of Cardiology New HT Guide.

Table 1: Definition of hypertension according to outpatient and home blood pressure.

\begin{tabular}{|c|c|c|c|}
\hline Category & Systolic blood pressure (mmHg) & Diastolic Blood Pressure (mmHg) \\
\hline Outpatient blood pressure & $\geq 140$ & and/ or & $\geq 90$ \\
\hline Ambulatory blood pressure & & & $\geq 85$ \\
\hline Day (or awake) & $\geq 135$ & and/ or & $\geq 70$ \\
\hline Night (or asleep) & $\geq 120$ & and/or & $\geq 80$ \\
\hline 24 hours & $\geq 130$ & and/or & $\geq 85$ \\
\hline Home blood pressure & $\geq 135$ & and/or & \\
\hline
\end{tabular}

Although hypertension is a significant chronic disease, it is known that a considerable number of patients with hypertension are not aware of their condition and are not diagnosed, and those diagnosed do not receive regular treatment and control [1,4]. Only $50 \%$ of individuals with hypertension in the world are aware that they are hypertensive and $50 \%$ of those receive antihypertensive treatment, but only $50 \%$ of those receiving antihypertensive treatment can control hypertension [9]. Among the individuals with hypertension, the rate of awareness of their condition has increased from $50 \%$ to $70 \%$ in the USA. In parallel with that, the rate of hypertensive patients who received treatment increased from $31 \%$ to 59\%. The figures in Europe are also similar. However, the rates of controlling hypertension are not at acceptable levels. While the rate of controlling hypertension in the USA was $29 \%$ two decades ago, it has reached only 34\% today. Hypertension treatment rates in Europe are also lower than those in the USA. Only $8 \%$ of hypertensive patients in Europe have controlled hypertension $[4,10]$. While the USA and France are in the best 
position in controlling hypertension (32-33\%), this rate is 1525\% in Western Europe and 5-9\% in England and 5-6\% in Eastern Europe.

The data obtained from the latest PatenT $[4,11]$ and HinT $[4,12]$ studies conducted in Turkey have indicated that hypertension is extremely widespread in Turkey but not adequately treated. Hypertension control rate is $8 \%$ in all hypertensives according to 2003 data $[4,11]$ while it is $13.6 \%$ according to 2007 data. It is $21 \%[4,11]$ in those receiving antihypertensive treatment according to 2003 data while it is $26.5 \%$ [4,12] according to 2007 data. As a result, the control rates of hypertension are very low both in Turkey and all over the world [4]. because of these data, the control rate does not exceed $25-30 \%$ even under the optimum conditions. This data is very important, as it shows that approximately $70 \%$ of hypertensive patients are either not treated at all or poorly treated [3]. As such, there are three main purposes of the evaluation of hypertensive patients. It is then necessary to evaluate the lifestyle, identify the diseases associated with other cardiovascular risk factors affecting prognosis and treatment, to reveal the identifiable causes of hypertension, to determine whether there is target organ damage and cardiovascular disease [13].

Successful coping with hypertension requires patients to be determined in maintaining and achieving blood pressure checks, to comply with other recommendations as well as medication, to obtain knowledge about blood pressure, and to continue checks. Effective interventions can be made to control hypertensive patients' blood pressure and improve their quality of life. These may include more appropriate combinations of providing healthcare services, information, counseling, reminders, selfmonitoring, support, and family treatment. It has been reported that the targeted blood pressure has been reached in the USA thanks to the "National High Blood Pressure Training Programs" and the blood pressure of hypertensive patients has decreased, as a result, the prevalence of hypertension, stroke and coronary heart disease has diminished [3]. All in all, since hypertension is a modifiable and preventable condition, it is necessary to know the prevalence of hypertension and the factors affecting it to shed light on public health studies and to take primary preventive measures. Future studies on this subject are important in this respect.

\section{Material and Method}

The population of this cross-sectional study consists of the individuals aged between 20-65 ( $\mathrm{N}=86245)$ living in the district of Artuklu, Mardin Province. The proportioned selection was made using the stratified random sampling method and the sampled individuals were represented in the sample at the rate of each Family Healthcare Centre population, taking the Family Healthcare Center (ASM) populations located in the Artuklu district center into consideration. By using the Epi Info Statcalc calculation software, the number of $\mathrm{n}=1055$ samples was determined with a prevalence of $50 \%$ unknown prevalence with 0.003 error margin in a $95 \%$ confidence interval. After being informed about the research, individuals aged between 20-65 years old who agreed to participate were included in the procedure. The study data were collected between October 2017 and February 2018. A questionnaire of 27 items created with the hypertension literature containing sociodemographic characteristics and early diagnosis methods was used as a data collection tool. The inclusion criteria for the study group was to be between the ages of 20-65 years. Exclusion criteria in the study included having any physical illness that prevents cooperation, having any audio-visual and cognitive dysfunction that would prevent communication, not being able to be reached despite three visits and not accepting the interview. The data were collected with the help of nursing or midwifery senior students. To the interviewer students, A total of 32 hours of training was provided by 4 experts in groups of 5 .

The blood pressure of the people who agreed to participate in the study in Family Healthcare Centres was measured by the same person for three days. The blood pressure was measured by the same interviewer twice with a sphygmomanometer from the right arm after at least 5-10 minutes of break. Diastolic and systolic blood pressures were determined by averaging these two measurements. Anthropometric measurements (height and weight) were also made by people with the same training using standardized measurement methods. The dependent variable of this study is the presence of hypertension and its independent variables are sociodemographic characteristics. The data collected in the procedure were analyzed using the Statistical Package for Social Science for Windows (SPSS 16.0) program. The measured variables are presented with mean scores $( \pm)$ and standard deviation (SD) while categorical variables are presented with numbers and percentages (\%). In the data analysis, the chi-square test was used, and the significance level was taken as $\mathrm{p}<0.05$.

\section{Ethical Approval}

This study is a project of Mardin Artuklu University Scientific Research (MAÜ-BAP-17-SYO-25). Relevant support has been received from Mardin Artuklu University Scientific Research Project Coordinators. The results of the study were also presented at the ${ }^{I^{\text {st }}}$ International II ${ }^{\text {nd }}$ National Public Health Nursing Congress in Ankara on April 23-26, 2018 as a verbal declaration. Ethical permission was obtained from Mardin Artuklu University's non-interventional research ethics committee and institutional permission was obtained from Mardin Provincial Health Directorate.

\section{Findings and Discussion}

$68.0 \%$ of the individuals included in the study are under 40 years old and $57.2 \%$ are female. Considering the educational status, the rate of illiterate individuals is $23.9 \%$ while the rate of university graduates is only $5.1 \%$ (Table 2). It is seen that $53.2 \%$ of individuals are working. When drinking alcohol and smoking status of individuals was evaluated, it was determined that $59.7 \%$ 
of the individuals did not smoke and $10 \%$ of them drank alcohol. It was also found that only $12.6 \%$ of the individuals included in the study exercised while $46.5 \%$ of them never exercised. $50.5 \%$ of the individuals' body mass index (BMI) was between 18.524.99 (Table 3). $42.3 \%$ of the individuals included in the study had close relatives who were diagnosed with hypertension. It was found that $79.9 \%$ of them did not have any chronic disease.
It was striking that $55.7 \%$ of them had rarely their blood pressure measured. $40.0 \%$ of them preferred to drink lemon juice when their blood pressure was high (Table 4). A significant correlation was found between age, marital status, educational level, and body mass indexes and the presence of hypertension of the individuals participating in the study $(\mathrm{P}<0.05)$ (Table 5).

Table 2: Demographic Characteristics, Drinking Alcohol and Smoking, Exercising and Body Mass Index Status of the Individuals Included in the Study.

\begin{tabular}{|c|c|c|c|}
\hline Demographic Characteristics & $\mathbf{n}$ & \multicolumn{2}{|c|}{$\%$} \\
\hline \multicolumn{4}{|l|}{ Gender $(n=1054)$} \\
\hline Female & 603 & \multicolumn{2}{|c|}{57,2} \\
\hline Male & 451 & \multicolumn{2}{|c|}{42,8} \\
\hline \multicolumn{4}{|l|}{ Age groups (n=1054) } \\
\hline 20-29 Years & 401 & \multicolumn{2}{|c|}{38,0} \\
\hline 30-39 Years & 316 & \multicolumn{2}{|c|}{30,0} \\
\hline 40-49 Years & 182 & \multicolumn{2}{|c|}{17,3} \\
\hline 50-65 Years & 155 & \multicolumn{2}{|c|}{14,7} \\
\hline \multicolumn{4}{|l|}{ Marital status ( $\mathrm{n}=1054)$} \\
\hline Married & 664 & \multicolumn{2}{|c|}{63,0} \\
\hline Single & 390 & \multicolumn{2}{|c|}{37,0} \\
\hline \multicolumn{4}{|l|}{ Educational status $(\mathrm{n}=1054)$} \\
\hline Illiterate & 252 & \multicolumn{2}{|c|}{23,9} \\
\hline Primary school & 347 & \multicolumn{2}{|c|}{32,9} \\
\hline Secondary / High School & 401 & \multicolumn{2}{|c|}{38,0} \\
\hline University and above & 54 & \multicolumn{2}{|c|}{5,1} \\
\hline \multicolumn{4}{|l|}{ Employment status ( $\mathrm{n}=1054)$} \\
\hline Working & 561 & \multicolumn{2}{|c|}{53,2} \\
\hline Non-working & 493 & \multicolumn{2}{|c|}{46,8} \\
\hline $\begin{array}{c}\text { Smoking status }(\mathrm{n}=1054) \\
\text { Smoking } \\
\text { Non-smoking } \\
\text { Drinking Alcohol Status ( } \mathrm{n}=1054) \\
\text { Yes } \\
\text { No }\end{array}$ & & $\begin{array}{l}425 \\
629 \\
\\
105 \\
949\end{array}$ & $\begin{array}{l}40,3 \\
59,7 \\
10,0 \\
90,0\end{array}$ \\
\hline $\begin{array}{c}\text { Exercising }(\mathrm{n}=1054) \\
\text { Never } \\
\text { Occasionally } \\
\text { Always } \\
\text { Body Mass Index }(\mathrm{n}=1054) \\
<18.5 \\
18.5-24,99 \\
25 \geq \\
30 \geq \\
40 \geq\end{array}$ & & $\begin{array}{r}490 \\
431 \\
133 \\
\\
32 \\
532 \\
334 \\
117 \\
39\end{array}$ & $\begin{array}{r}46,5 \\
40,9 \\
12,6 \\
\\
\\
3,0 \\
50,5 \\
31,7 \\
11,1 \\
3,7\end{array}$ \\
\hline Total & & 1054 & 100,0 \\
\hline
\end{tabular}


Table 3: Knowledge Status of the Individuals Included in the Study About Hypertension.

\begin{tabular}{|c|c|c|}
\hline Hypertension Knowledge Status & n & $\%$ \\
\hline \multicolumn{3}{|c|}{ Is there any relative diagnosed with hypertension in the family? $(n=1054)$} \\
\hline Yes & 446 & 42,3 \\
\hline No & 608 & 57,7 \\
\hline \multicolumn{3}{|l|}{ Degree of relationship } \\
\hline Close relative & 409 & 91,7 \\
\hline Distant relative & 37 & 8,3 \\
\hline \multicolumn{3}{|c|}{ Do you have any chronic disease you know? $(\mathrm{n}=1054)$} \\
\hline Yes & 212 & 20,1 \\
\hline No & 842 & 79,9 \\
\hline \multicolumn{3}{|l|}{ Chronic disease* } \\
\hline Hypertension & 74 & 34,9 \\
\hline Diabetes mellitus & 48 & 22,6 \\
\hline Renal disease & 34 & 14,6 \\
\hline Cardiac disease & 27 & 12,7 \\
\hline Other & 32 & 15,2 \\
\hline \multicolumn{3}{|l|}{ Is hypertension a disease? $(\mathrm{n}=1054)$} \\
\hline Yes & 858 & 81,4 \\
\hline No & 165 & 15,7 \\
\hline Not knowing / Undecided & 31 & 2,9 \\
\hline \multicolumn{3}{|c|}{$\begin{array}{l}\text { Do you have any knowledge about the diseases caused by hypertension? } \\
\qquad(\mathrm{n}=1054)\end{array}$} \\
\hline Yes & 614 & 58,3 \\
\hline No & 411 & 39,0 \\
\hline Not knowing / Undecided & 29 & 2,7 \\
\hline \multicolumn{3}{|l|}{ Which diseases $(\mathrm{n}=1054)$} \\
\hline Vascular diseases & 395 & 37,5 \\
\hline Stroke (paralysis) & Stroke & 54,2 \\
\hline Renal diseases & 243 & 23,1 \\
\hline Ophthalmic diseases & 421 & 39,9 \\
\hline Cardiac diseases & 426 & 40,4 \\
\hline \multicolumn{3}{|c|}{ Frequency of measuring blood pressure $(n=1054)$} \\
\hline Every day & 47 & 4,5 \\
\hline Once in a week & 70 & 6,6 \\
\hline When sickened & 350 & 33,2 \\
\hline Rarely & 304 & 28,8 \\
\hline Never & 283 & 26,9 \\
\hline \multicolumn{3}{|c|}{ Do you do anything special when your blood pressure is high? $(\mathrm{n}=1054)^{*}$} \\
\hline Yes & 713 & 67,6 \\
\hline No & 341 & 32,4 \\
\hline \multicolumn{3}{|l|}{ Going to the emergency service* } \\
\hline $\begin{array}{l}\text { Yes } \\
\text { No }\end{array}$ & $\begin{array}{l}258 \\
796\end{array}$ & $\begin{array}{l}24,5 \\
75,5\end{array}$ \\
\hline \multicolumn{3}{|l|}{ Drinking lemon juice* } \\
\hline Yes & 422 & 40,0 \\
\hline No & 632 & 60,0 \\
\hline
\end{tabular}




\section{Annals of Reviews and Research}

\begin{tabular}{|c|c|c|}
\hline Eating garlic* & & \\
\hline Yes & 172 & 16,3 \\
\hline No & 882 & 83,7 \\
\hline
\end{tabular}

*More than one option has been chosen.

Table 4: Comparison of Factors Related to Hypertension of the Individuals Included in the Study.

\begin{tabular}{|c|c|c|c|c|c|c|c|c|}
\hline \multirow[t]{2}{*}{ Hypertension } & \multicolumn{2}{|c|}{ Present } & \multicolumn{2}{|c|}{ Non-present } & \multicolumn{2}{|c|}{ Total } & \multirow[b]{2}{*}{$\mathbf{P}$} & \multirow[b]{2}{*}{$\mathbf{X}^{2}$} \\
\hline & $\mathbf{n}$ & $\%$ & $\mathbf{n}$ & $\%$ & $\mathbf{n}$ & $\%$ & & \\
\hline \multicolumn{9}{|l|}{ Age } \\
\hline 20-29 Years & 26 & 6,5 & 375 & 93,5 & 401 & 100 & .000 & 134.84 \\
\hline 30-39 Years & 55 & 17,4 & 261 & 82,6 & 316 & 100 & & \\
\hline 40-49 Years & 52 & 28,6 & 130 & 71,4 & 182 & 100 & & \\
\hline 50-65 Years & 75 & 48,4 & 80 & 51,6 & 155 & 100 & & \\
\hline \multicolumn{9}{|l|}{ Marital status } \\
\hline Married & 165 & 24,8 & 499 & 75,2 & 664 & 100 & .000 & 29.64 \\
\hline Single & 43 & 11,0 & 347 & 89,0 & 390 & 100 & & \\
\hline \multicolumn{9}{|l|}{ Educational status } \\
\hline Illiterate & 77 & 30,6 & 175 & 69,4 & 252 & 100 & & \\
\hline Primary school & 64 & 18,4 & 283 & 81,6 & 347 & 100 & .000 & 39.59 \\
\hline Secondary / High School & 49 & 12,2 & 352 & 87,8 & 401 & 100 & & \\
\hline University and above & 18 & 33,3 & 36 & 66,7 & 54 & 100 & & \\
\hline \multicolumn{9}{|l|}{ Body Mass Index } \\
\hline$<18.5$ & 3 & 9,4 & 29 & 90,6 & 32 & 100 & & \\
\hline $18.5-24.99$ & 73 & 13,7 & 459 & 86,3 & 532 & 100 & & \\
\hline $25 \geq$ & 68 & 20,4 & 266 & 79,6 & 334 & 100 & .000 & 69.61 \\
\hline $30 \geq$ & 41 & 35,0 & 76 & 65,0 & 117 & 100 & & \\
\hline $40 \geq$ & 23 & 59,0 & 16 & 41,0 & 39 & 100 & & \\
\hline \multicolumn{9}{|c|}{$\begin{array}{l}\text { Any relative diagnosed with hyper- } \\
\text { tension in the family }\end{array}$} \\
\hline Yes & 107 & 24,0 & 339 & 76,0 & 446 & 100 & .002 & 8.84 \\
\hline No & 101 & 16,6 & 507 & 83,4 & 608 & 100 & & \\
\hline \multicolumn{9}{|c|}{ Having any known chronic disease } \\
\hline Yes & 99 & 42,1 & 136 & 57,9 & 235 & 100 & .000 & 95.74 \\
\hline No & 109 & 13,3 & 710 & 86,7 & 819 & 100 & & \\
\hline
\end{tabular}

Table 5: Hypertension Prevalence of the Individuals Included in the Study in terms of Gender.

\begin{tabular}{|c|c|c|c|}
\hline Hypertension Status & & $\mathbf{n}$ & $\%$ \\
\hline \multicolumn{4}{|c|}{ According to previous hypertension guidelines (2013) } \\
\hline \multirow[t]{3}{*}{ Female } & Normotensive & 493 & 81,8 \\
\hline & Hypertensive & 110 & 18,2 \\
\hline & Total & 603 & 100,0 \\
\hline \multirow[t]{3}{*}{ Male } & Normotensive & 353 & 78,3 \\
\hline & Hypertensive & 98 & 21,7 \\
\hline & Total & 451 & 100,0 \\
\hline \multicolumn{4}{|c|}{ According to new hypertension guidelines (2013) } \\
\hline \multicolumn{4}{|c|}{$(2018)$} \\
\hline
\end{tabular}


Annals of Reviews and Research

\begin{tabular}{|c|c|c|c|}
\hline Female & Normotensive & 271 & 44,9 \\
\hline & Hypertensive & 332 & 55,1 \\
\hline & Total & 603 & 100,0 \\
\hline Male & Normotensive & 129 & 28,6 \\
\hline & Hypertensive & 322 & 71,4 \\
\hline & Total & 451 & 100,0 \\
\hline According to previous data (2013) & Hypertension Prevalence in General Population & 19,7 \\
\hline According to new data (2018) & Hypertensive & 208 & 62 \\
\hline
\end{tabular}

In this study conducted in the urban setting, the prevalence of hypertension among the individuals aged between 20- 65 years living in Mardin, and the factors affecting them were examined. In this study, it was found that the prevalence of hypertension increased with age as in previous studies. When evaluated according to age groups, it can be suggested that one of both individuals in the 40-49 age group and one in every 3 individuals in the 50-65 age group have hypertension. Similar findings were obtained in TURDEP-I, TURDEP-II, and PATENT studies conducted in our country, and the study conducted in the US [14-17]. A significant correlation was found between the educational levels and marital status of the participants in the study and the presence of hypertension. A study conducted in Los Angeles has shown that educational level or health literacy is associated with hypertension [18]. These results are in line with the results of our study. It was revealed that more than half of the participants (55.7\%) rarely had their blood pressure measured. In another study it was found that $23.7 \%$ of the participants did not have their blood pressure measurements at all [19]. In a study conducted in Niğde, the rate of not having their blood pressure measured was $15.1 \%$ [20], and in another study conducted in Antalya, this rate was found to be $13.0 \%$ [21]. Oskay et al. [19] quoted that it was stated that only $1 \%$ of people did not have their blood pressure measured at all in a study conducted in the USA.

The findings of the present study showed that the rate of those who have never their blood pressure measured was dramatically higher compared to both domestic literature and the study conducted in the USA. It is known that the rate of having blood pressure measured is higher in developed countries. However, in Turkey regional differences, insufficient level of knowledge, and inadequate awareness are thought to be affecting factors. It is important to measure blood pressure at regular intervals in terms of early diagnosis of hypertension and the prevention of complications. The most important factor in having blood pressure measured at certain intervals is individual knowledge level. Hence, it is thought that having a high level of knowledge about hypertension will raise awareness and create conscious and sensitive behaviors in the public about this issue. It was determined that $81 \%$ of the individuals participating in the study knew that hypertension is a chronic disease and in terms of diseases caused by hypertension, $54 \%$ of them knew that they could get stroke (paralysis) as well as $40 \%$ of the heart disease and $37 \%$ of the vascular diseases. In a similar study, the fact that $92 \%$ of the patients regarded hypertension as a disease is similar to the results of our study [22]. It was determined that only $12 \%$ of the individuals participating in the study regularly exercised, almost half of them (46\%) never did so, and body mass index (BMI) of $50.5 \%$ of them was between 18.5-24.99. Mert et al. quoted that smoking, excessive alcohol consumption, and poor physical activity are major risk factors for hypertension [22]. In our study, it was found that the presence of hypertension increased as the body mass index increased. However, in our study, the correlation between the presence of hypertension and smoking, alcohol consumption, and non-exercising was found to be relatively low. This may arise from the fact that the cause-effect relationship could not be observed since the study is cross-sectional.

The mean systolic blood pressure of the whole group was $114.9 \pm 17.64 \mathrm{mmHg}(117.15 \pm 16.99 \mathrm{mmHg}$ in men, $112.70 \pm$ $17.89 \mathrm{mmHg}$ in women), and the mean diastolic blood pressure was $72.9 \pm 11.42 \mathrm{mmHg}$ (in men $74.13 \pm 10.65 \mathrm{mmHg}, 71.67 \pm$ $11.86 \mathrm{mmHg}$ in women). It was observed that the mean systolic and diastolic blood pressure increased with age in both genders and was higher in males than females. The results of the study are similar to Patent research. According to the 2013 data on the prevalence of hypertension, it was found to be $19.7 \%$. According to our study results, the prevalence of hypertension was higher in males $(21.7 \%)$ than females (18.2\%). In another similar study, the prevalence of hypertension was higher in males than females [19]. The results of the population-based epidemiological studies indicate that the prevalence of hypertension in adults in Turkey is $31.8 \%$ (36.1\% in women and $27.5 \%$ in men) [11]. It was seen that the findings of the present study were found to be lower than this value. This result can be explained by the fact that the present study was limited to one single region and thus cannot represent the whole of Turkey. According to the new hypertension guidelines of the American Society of Cardiology (according to 2018 data) [8], hypertension prevalence was found as $62 \%$ ( $p<0.001)$. Besides, the prevalence of hypertension increases 
with age. According to a study, $62.0 \%$ of the individuals never had blood pressure measured [23]. In another study, it has been determined that $32.2 \%$ of the people who have been screened have never their blood pressure measured [24]. Socio-cultural background, nutrition, the lifestyle of the communities, regional and prosperity discrepancies between countries are thought to be effective markers on health. Health-saving and improving initiatives such as taking blood pressure measurements at regular intervals, correcting incomplete or incorrect information, and conducting awareness-building campaigns can be extended by providing community-based participation.

\section{Conclusion and Recommendations}

In many countries, community-oriented educational campaigns have been reported to reduce hypertension burden and increase blood pressure control rates, as well as initiatives for positive lifestyle changes such as healthy nutrition and taking medicine rationally [25]. Based on the present study data, it may be argued that hypertension prevalence is high in our country, while diagnosis and treatment rates are not sufficient. It is known that healthcare professionals have a decisive role in acquiring healthy lifestyle behaviors. For this reason, it will only be possible to change society effectively with a multidisciplinary, organized, and healthcare professional-oriented approach. Considering the health practices and sociocultural structure in our country, it is highly recommended to raise awareness about hypertension, provide a common ground for different definitions and values and treatment options in different guidelines, disseminate blood pressure measurements for early detection of the problem of hypertension development, build effective treatment practices and awareness for blood pressure control, as well as to conduct community, scans aimed at increasing their levels, and to promote health-promoting initiatives that guide healthy lifestyle change.

\section{References}

1. Çöl M, Özdemir O, Ocaktan ME (2006) Treatment-Control Conditions and Behavioral Factors among Hypertensives Over 35 Years of Age in Park Healthcare Center Region. Ankara University Medical Faculty Journal 59: 144-150.

2. Göçgeldi E, Alparslan Babayiğit M, Hassoy H, Açıkel C, Tașçı İ, et al. (2008) Evaluation of Perceived Quality of Life and Affecting Factors among Patients Diagnosed with Hypertension. Gülhane Medical Journal 50: 172-179.

3. Hacıhasanoğlu R (2009) Factors Affecting Treatment Compliance in Hypertension. TAF Prev Med Bull, 8(2): 167-172.

4. Altuğ Çakmak H, Arslan E, Erdine S (2009) Unmet Requirements in Hypertension. Turkish Cardiology Society Research Journal 37(7): 1-4.

5. Dönmez İ, Memioğlu T, Erdem, F (2015) Diagnosis and Treatment of Hypertension in the light of New Guidelines. Europan Journal of Health Sciences 1(1): 49-53.

6. Büyüköztürk K, İlerigelen B, Kabakçı G, Koylan N, Kozan Ö (2004) A comprehensive survey on Determining the Risk Profile of Patients with Hypertension in Turkey: I.C.E.B.E.R.G Study. Turkish Cardiology Society Research Journal 32: 344-349.
7. Öngen Z (2005) A tough social challenge: Hypertension. Clinical Development 18(2): 4-7.

8. Winally (2018) American Society of Cardiology New HT Guideline.

9. Erdine S (2008) How Well is Hypertension Controlled in Europe? J Hypertens 18: 1348-1349.

10. Müller DN, Luft FC (2006) Direct Renin İnhibition with Aliskiren in Hypertension and Target Organ Damage. ClinJ Am Soc Nephrol 1(2): 221-228.

11. Altun B, Arici M, Nergizoğlu G, Derici U, Karatan O, et al. (2005) Prevalence, Awareness, Treatment, and Control of Hypertension in Turkey (The Patent Study) in 2003. J Hypertens 23(3): 1817-1823.

12. (2008) Turkish Hypertension Incidence Survey. Turkish Hypertension and Renal Diseases Society. Antalya.

13. Balız ES (2013) Incidence of Hypertension and Risk Factors in Adults in Mahmudiye, Eskişehir. Eskişehir Osmangazi University Faculty of Medicine, Medical Specialty Thesis p. 10.

14. Altun B, Suleymanlar G, Utas C, Arınsoy T, Ateș K, et al. (2012) Prevalence, Awareness, Treatment, and Control of Hypertension in Adults with Chronic Kidney Disease in Turkey: Results from the CREDIT Study. Kidney Blood Press Res 36(1): 36-46.

15. Satman I, Yilmaz T, Sengül A, Salman S, Salman F, et al. (2002) Population-Based Study of Diabetes and Risk Characteristics in Turkey: Results of the Turkish Diabetes Epidemiology Study (TURDEP). Diabetes Care 25(9): 1551-1556.

16. Satman I, Omer B, Tutuncu Y, Kalaca S, Gedik S, et al. (2013) Twelve-year Trends in the Prevalence and Risk Factors of Diabetes and Prediabetes in Turkish Adults. Eur J Epidemiol 28(2): 169-180.

17. Ong KL, Cheung BMY, Man YB, Lau CP, Lam KSL (2006) Prevalence, Awareness, Treatment, and Control of Hypertension Among United States Adults 1999-2004. American Heart Association, Inc.

18. Williams MV, Baker DW, Ruth MP, Nurss JR (1998) Relationship of Functional Health Literacy to Patients' Knowledge of Their Chronic Disease, A Study of Patients with Hypertension and Diabetes. Arch Intern Med 158(2): 166-172.

19. Oskay ME, Önsüz FM, Topuzoğlu A (2010) Evaluation of the Knowledge, Attitudes and Opinions of the Patients about a Hypertension admitted to a Healthcare Center in Izmir. Adnan Menderes University Medical Journal 11(1): 3-9.

20. Boylu Ö (2006) The Prevalence and Awareness of Hypertension among the individuals at the Age of 40 and Over in Kemerhisar District of Niğde Province. Master Thesis. Kayseri: Erciyes University, Turkey.

21. Baharlı N, Aktekin MR (1999) Awareness of Hypertension and Affecting Factors among Those admitted to Selected Healthcare Centers in Antalya City Center. Health and Society 9(1): 8-12.

22. Mert H, Özçakar N, Kuruoğlu E (2011) A Multidisciplinary Special Study Module Research: Examining the Compliance of Hypertension Patients with Treatment. Turkish Journal of Family Practice 15(1): 7-12.

23. Teke N, Arslan S (2018) Determination of Adaptability and affecting Factors during Drug Treatment Compliance of Individuals Living in Rural Areas with Hypertension. Deuhfed 11(2): 120-128

24. Sengul S, Erdem Y, Akpolat T, Derici U, Sindel S, et al. (2013) Controlling Hypertension in Turkey: Not a Hopeless Dream. Kidney Int Suppl 3(4): 326-331.

25. Sözmen K, Ergör G, Ünal B (2015) Factors Affecting Hypertension Prevalence, Awareness, Treatment and Blood Pressure Control. Dicle Medical Journal 42 (2): 199-207. 
This work is licensed under Creative Commons Attribution 4.0 License

DOI:10.19080/ARR.2020.05.555675
Your next submission with Juniper Publishers will reach you the below assets

- Quality Editorial service

- Swift Peer Review

- Reprints availability

- E-prints Service

- Manuscript Podcast for convenient understanding

- Global attainment for your research

- Manuscript accessibility in different formats

( Pdf, E-pub, Full Text, Audio)

- Unceasing customer service

Track the below URL for one-step submission https://juniperpublishers.com/online-submission.php 